\title{
GSM Voice based Performance Analysis of Reactive Routing Protocols of MANETs
}

\author{
Meenakshi Sharma \\ M.Tech Scholar \\ SBSSTC, \\ Ferozepur
}

\author{
Navdeep Kaur \\ A.P-ECE \\ SBSSTC, \\ Ferozepur
}

\author{
Gurjeevan Singh \\ DIC-ECE \\ SBSSTC(P.W.), \\ Ferozepur
}

\begin{abstract}
A mobile ad hoc network is a multihop wireless network formed by a group of wireless mobile nodes communicating with each other without any centralized infrastructure .This research paper evaluates the performance of AODV and DSR routing protocols in mobile ad hoc network using high quality GSM voice. Average end to end delay, packet loss and traffic sent are the performance metrics used to compare the above said routing protocols using NS-2 simulator. This simulation work shows that AODV is much better as compared to DSR on the basis of discussed parameters.
\end{abstract}

\section{Keywords}

AODV, DSR, End -to-End delay, NS-2.

\section{INTRODUCTION}

Ad hoc networks also called infrastructure less networks are complex distributed system which consists of wireless links between the nodes and each node also works as a router to forward the data on behalf of the other nodes. The nodes are free to join or leave the network without any restriction. Thus the networks have no permanent or fixed infrastructure. This is helpful in disaster recovery situations and the places with non-existing or damaged communication infrastructure where rapid deployment of a communication network is needed. Ad- hoc networks can also be useful for conferences where people participating in the conference can form a temporary network without engaging the services of any pre-existing network. We call the users or devices creating the network as nodes. Each node is equipped with a radio transmitter and receiver which allows it to communicate with the remaining nodes. Nodes in an ad-hoc network can generate data and forward it to any other node in the network. The primary challenge in building a MANET is equipping each device to continuously maintain information required to properly route traffic[15].

\section{ROUTING IN MANET}

Routing is the process which involves exchange of information from one station to another in the network. The nodes in MANET act both as a host and a router and communicate with each other without any centralized infrastructure [16]. Routing protocols of mobile ad-hoc networks need different approaches from pre-existing Internet protocols, since most of the existing Internet protocols were designed to support routing in a network with fixed infrastructure. It is one of the core issues in mobile ad-hoc network. An effective routing mechanism results in successful deployment of mobile ad-hoc networks. Routing protocols use several metrics to find out the best path for routing the packets from source to its destination. These metrics are standard measurements that could be number of hops, which is used by the routing algorithm to determine the optimal path for the packet to its destination. The process of path determination is that, routing algorithms initialize and maintain routing tables, which contain the total route information for the packet. This route information varies for one routing algorithm to another.

\section{BRIEF DESCRIPTION OF AODV \& DSR ROUTING PROTOCOLS}

\subsection{AODV}

Ad Hoc on-Demand Distance Vector (AODV) offers low network utilization and uses destination sequence number to ensure loop freedom. It is a reactive routing protocol implying that it requests a route when needed .AODV also provide quick deletion of invalid routes breakages[15]. An important feature of AODV is that it uses a destination sequence number, which corresponds to a destination node that was requested by a routing sender node. The destination itself provides the number along with the route it has to take to reach from the request sender node up to the destination. If there are multiple routes from a request sender to a destination, the sender takes the route with a higher destination sequence number. This ensures that the ad hoc network protocol remains loop-free. Routing tables used by AODV store destination and next hop IP addresses as well as destination sequence number [3].

\subsection{DSR}

Dynamic Source Routing (DSR) is a reactive protocol i.e. it doesn't use periodic advertisements. It discovers the routes when necessary and then maintains them. Source routing is a routing technique in which the sender of a packet determines the complete sequence of nodes through which the packet has to pass; the sender explicitly lists this route in the packet's header, identifying each forwarding "hop" by the address of the next node to which to transmit the packet on its way to the destination host. There are two significant stages in working of DSR: Route Discovery and Route Maintenance. Route discovery operation is used when routes to unknown hosts are required. Route maintenance operation is used to monitor the correctness of established routes and to initiate route discovery if a route fails[17]. In addition to the address of the original initiator of the request and the target of the request, each route request packet contains a route record, in which is accumulated a record of the sequence of hops taken by the route request packet as it is propagated through the network during this route discovery. As the route is part of the packet itself, routing loops, either short lived or long-lived, cannot be formed as they can be immediately detected and eliminated [3]. 


\section{SIMULATION SETUP}

The simulations are performed using Network Simulator 2 (NS-2.34). In Table 1, we have summarized the model parameters that have been used for our experimental work.

\begin{tabular}{|c|c|}
\hline Parameters & Value \\
\hline Protocols & AODV \& DSR \\
\hline Simulator & NS-2.34 \\
\hline Nodes & $20,40,50$ \\
\hline Simulation Area & $5 \mathrm{Km} * 5 \mathrm{Km}$ \\
\hline Packet Size & $1 \mathrm{~kb}$ \\
\hline MAC Protocol & IEEE $802.11 \mathrm{~b}$ \\
\hline Mobility Model & Random waypoint \\
\hline Traffic & High quality GSM \\
& Voice \\
\hline Pause Time & $50 \mathrm{sec}$ \\
\hline Simulation Time & $900 \mathrm{sec}$ \\
\hline Node Speed & $10 \mathrm{~m} / \mathrm{sec}$ \\
\hline
\end{tabular}

\section{PERFORMANCE METRICS}

MANET has number of qualitative and quantitative metrics that can be used to compare ad hoc routing protocols. This paper has been considered for the following metrics to evaluate the performance of mobile adhoc network routing protocols.

5.1 Average End-to-End Delay: It is defined as the average time taken by data packets to propagate from source to destination across a MANET. This is the difference between sending time of a packet and receiving time of a packet. This includes all the possible delays caused by buffering during route discovery latency, queuing at the interface queue, retransmission delays at the MAC, and propagation and transfer times [2, 4].

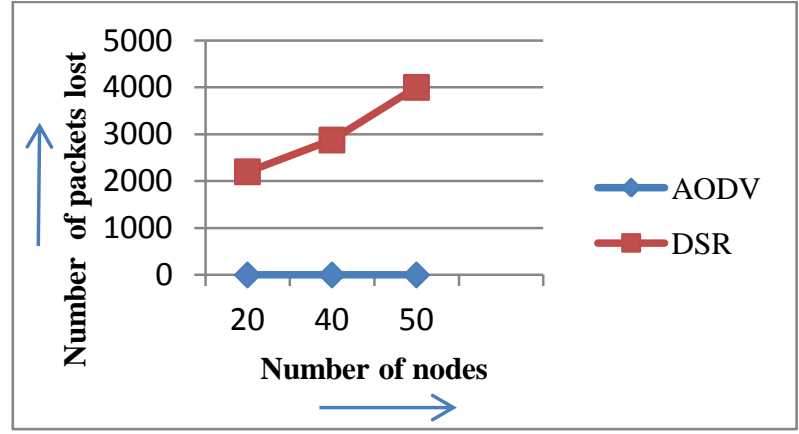

Figure 2: Packet loss for different number of nodes using AODV and DSR protocols

Figure. 2 shows that AODV has less value of number of packet lost than DSR. AODV has zero value for number of packet lost but the value for DSR increases as the number of nodes increases.
5.2 Packet Loss: It occurs when one or more packets travelling across a network fail to reach their destination. Packet loss can be caused by a number of factors, including signal degradation over the network, oversaturated and highly congested network links, corrupted and faulty packets rejected, faulty networking hardware [14].

5.3 Traffic Sent: During transmission of data in simulated ad hoc network routing traffic sent by all wireless nodes. In other words it shows that how many traffic sent by source node to destination node with the help of intermediate node in simulated area using MANET routing protocol [5].

\section{RESULTS AND OBSERVATIONS}

In this Section, we compare the capabilities of the two routing protocol i.e. AODV \& DSR studied in this research paper. Performance metrics are calculated from trace file, with the help of AWK program. The simulation results are shown in the following section in the form of line graphs.

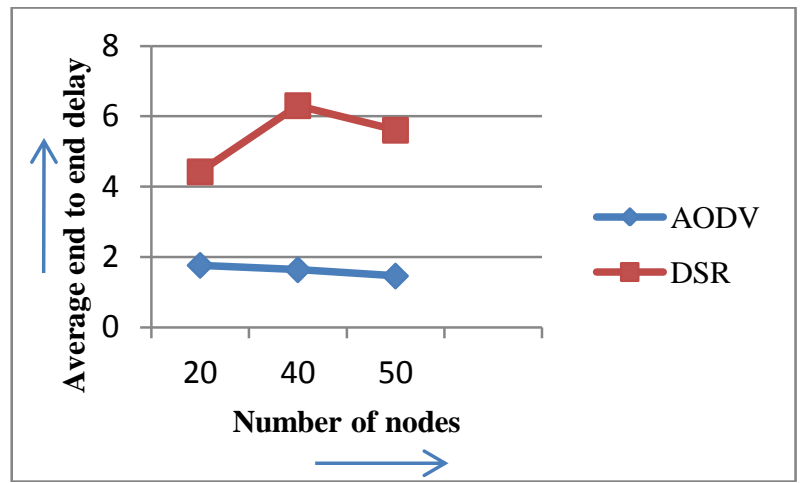

Figure 1: Average end-to-end delay for different number of nodes using AODV and DSR protocols

From Figure. $1 \mathrm{We}$ can observe that, end to end delay is more in DSR as compared to AODV. DSR has the highest value for end-to-end delay but in the case of AODV, as the number of nodes increases the value of end-to-end delay decreases.

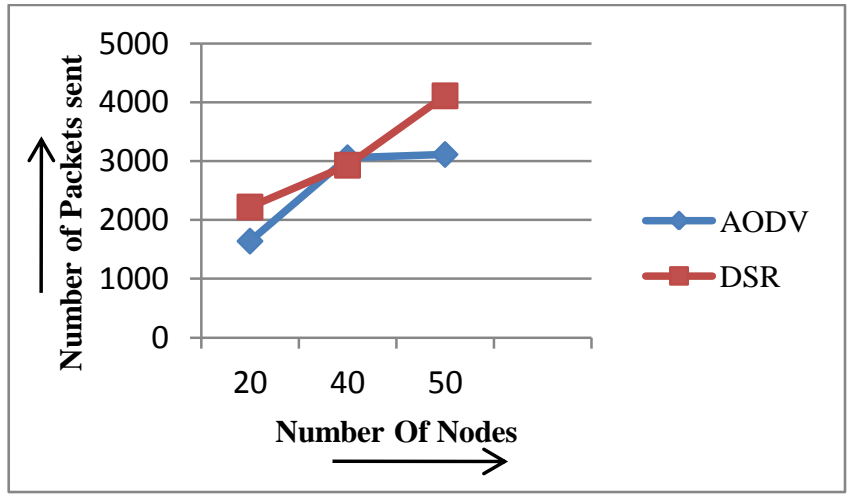

Figure 3: Traffic sent for different number of nodes using AODV and DSR protocols

Figure. 3 shows the results of how many traffic sent by source node to destination node with the help of intermediate node in simulated area using MANET routing protocol. In DSR protocol traffic sent rate is high in comparison of DSR protocol except for 40 nodes, in the case of 40 nodes traffic sent rate of AODV is more than DSR after end of simulation time. 


\section{CONCLUSION}

This work is an attempt towards a comprehensive performance evaluation of two commonly used MANET routing protocols (AODV and DSR).In this paper, using the latest simulation environment NS-2, we evaluated the performance of the two widely used reactive routing protocols using packet -level simulation. The simulation characteristics used in this research that is, average end-to-end delay, packet loss and traffic sent are unique in nature $\&$ are very important for detailed performance evaluation of any networking protocol. We can summarize our final conclusion from our experimental results as follows:

- With increase in number of nodes , number of packets sent with DSR is more as compared to AODV

- No of packets dropped is also more in case of DSR than AODV

- Packets lost in case of DSR are much more than AODV due to which AODV is counted the best.

- Average end to end delay is very large in case of DSR than that of AODV

In short AODV has the best all round performance.

\section{FUTURE SCOPE}

In the future some complex simulations can be carried out using other existing performance metrics, in order to gain a more in depth performance analysis of the adhoc routing protocol.

\section{REFERENCES}

[1] Vishal Sharma, Harsukhpreet Singh , Mandip Kaur, Vijay Banga "Performance evaluation of reactive routing protocols in MANET networks using GSM based voice traffic applications" Optik - Int. J. Light Electron Opt. (2012), http://dx.doi.org/10.1016/j.ijleo.2012.06.040

[2] Neetu, Parveen Kumar,"Simulation Analysis and Comparison of DSDV And AODV Routing Protocols for MANET", International Journal of Advanced Engineering Research and Studies, Vol. 1, Issue 3, AprilJune, 2012, pp. 220-222.

[3] Dr. V. B. Narsimaha,"The Performance Comparison of an AODV, DSR, DSDV and OLSR Routing Protocols in Mobile Ad-Hoc Networks", Journal of Computer Applications, Vol.5, Issue 2, 2012.

[4] P. Manickam, T. Guru Baskar, M. Girija, Dr. D. Manimegalai, "Performance Comparisons of Routing Protocols in Mobile Ad Hoc Networks", International Journal of Wireless \& Mobile Networks (IJWMN) Vol. 3, No. 1, February 2011, pp. 98- 106.Tavel, P. 2007 Modeling and Simulation Design. AK Peters Ltd.

[5] Kuldeep Vats, Monika Sachdeva, Dr. Krishan Saluja,“ Simulation and performance Analysis of OLSR, GRP, DSR Routing Protocol using OPNET", International Journal of Emerging trends in Engineering and Development, Vol. 2, Issue 2, March 2012, pp. 390-404.

[6] V.Ramesh, Dr. P.Subbaiah, N.Koteshwar Rao, M. Janardhana Raju,"Performance Comparison and Analysis of DSDV and AODV for MANET",International Journal on Computer Science and Engineering,Vol. 02,No. 02,2010,pp. 183-188.
[7] Dr. V.B.Narsimaha,"The Performance Comparison of an AODV,DSR,DSDV and OLSR Routing Protocols in Mobile Ad-Hoc Networks ", Journal of Computer Applications, Vol.5,Issue 2,2012.

[8] Tamilarasan-Santhamurthy,"A Quantitative Study and Comparison of AODV,OLSR and TORA Routing Protocols in MANET"International Journal of Computer Science Issues, Vol. 9,Issue 1, No 1, January 2012,pp.364-369,2012.

[9] Adel.S.El ashheb,"Performance Evaluation of AODV and DSDV Routing Protocol in wireless sensor network Environment",Proceedings International Conference on Computer Networks and Communication Systems (CNCS2012) IPCSIT, Vol. 35,2012,Singapore,pp.55-62.

[10] Parulpreet Singh, Ekta Barkhodia, Gurleen Kaur Walia,"Performance Study of Different Routing Protocols (OLSR,DSR, AODV) Under Different Traffic Loads and with Same Number of Nodes in MANET using OPNET", International Journal of Electronics \& Communication Technology, Vol. 3, Issue 1, Jan. March 2012, pp. 155-157, 2012

[11] Gowrishankar.S, SubirKumarSarkar, T. G. Basavaraju, "Analysis of AOMDV and OLSR Routing Protocols Under Levy-Walk Mobility Model and Gauss-Markov Mobility Model for Ad Hoc Networks", International Journal on Computer Science and Engineering, Vol. 02, No. 04, 2010,pp. 979-986, 2010.

[12] Anuj K. Gupta , Dr. Harsh Sadawarti, Dr. Anil K. Verma "Performance analysis of AODV, DSR \& TORA Routing Protocols" International Journal of Engineering and Technology, Vol.2, No.2, April 2010 ISSN: 17938236.

[13] Mounir Frikha, Manel Maamer,"Implementation and simulation of OLSR protocol with QoS in Ad Hoc Networks",Proceedings of the second international symposium on communications, control and signal processing, (ISCCSP'06),13-15 MARCH 2006, Marrakech Morocco.

[14] Jyotsna Rathee, Dr. A K Verma,"Simulation, Analysis and Comparison of DSDV Protocol in MANETS", Thesis in Thapar University Patiala, May 2009.Y.T. Yu, M.F. Lau, "A comparison of MC/DC, MUMCUT and several other coverage criteria for logical decisions", Journal of Systems and Software, 2005, in press.

[15] Swati Bhasin, Ankur Gupta,Puneet Mehta" Comparison of AODV, OLSR and ZRP Protocols in Mobile Ad-hoc Network on the basis of Jitter" International Journal of Applied Engineering Research, ISSN 0973-4562 Vol.7 No.11 (2012)

[16] Latif Ullah Khan, Faheem Khan, M. N Khan" On Effect of Network Density on the Performance of MANET Routing Protocols" Proceedings of international conference on circuits,power nd computing technologies(ICCPCT), 20-21 march 2013, Nagercoil , India 1089-1092.

[17] Floriano De Rango , Juan-Carlos Cano , Marco Fotino Carlos Calafate , Pietro Manzoni ,Salvatore Marano "OLSR vs DSR: A comparative analysis of proactive and reactive mechanisms from an energetic point of view in wireless ad hoc networks" Computer Communications 31 (2008) 3843-3854. 